\title{
Modeling Covariates of Infant and Child Mortality in Kenya
}

\author{
Stephen Muthii Wanjohi ${ }^{1}$, Daniel Mwangi Muriithi ${ }^{2}$ \\ ${ }^{1}$ Department Statistics and Actuarial Science, Jommo Kenyatta University of Agriculture and Technology, Nairobi, Kenya \\ ${ }^{2}$ Department Statistics and Actuarial Science, Moi University, Eldoret, Kenya
}

Email address:

wanjohi8280@yahoo.com (S. M. Wanjohi), mwangidii@gmail.com (D. M. Muriithi)

\section{To cite this article:}

Stephen Muthii Wanjohi, Daniel Mwangi Muriithi. Modeling Covariates of Infant and Child Mortality in Kenya. International Journal of Data Science and Analysis. Vol. 6, No. 3, 2020, pp. 90-98. doi: 10.11648/j.ijdsa.20200603.13

Received: May 22, 2019; Accepted: July 9, 2019; Published: August 4, 2020

\begin{abstract}
Mortality of children under the age of five has been target of public health policies. There has been a significant decline in under-five mortality in the twenty first century in almost all countries several studies have been conducted to identify covariates of Infant and Child Mortality in Kenya but none of these used recent data and none has included HIV/AIDs as a risk factor. This study aims at examining bio-demographic, socio-economic and environmental mortality in Kenya. Two methods of the logistic regression and survival analysis method are used. The results of the study show that HIV status of the mother and lengths of the preceding birth interval were significantly associated with both Infant and Child Mortality. Other significant covariates include birth order, age of the mother at birth of the child, sex of the child, education of the mother and father and wealth index.
\end{abstract}

Keywords: Infant, Mortality, Covariates

\section{Introduction}

Mortality of children under the age of five has been target of public health policies. There has been a significant decline in under-five mortality in the $21^{\text {st }}$ century in almost all countries regardless of initial levels and economic factors, although the rate of decline has been different for different regions. According to the results of the Kenya Demographic and Health Survey (KDHS) conducted in 2008-2009 under five mortality has reduced from 115 deaths per 1000 live births in 2003.

Infant mortality rate is one of the most important sensitive indicators of the socio-economic and health status of a community. Child deaths are commonly as a result of several risk factors. [13] The relative importance of these factors in relation to Infant and Child Mortality risk varies with the level of social and economic well-being of a society. [16] Reported that children with greater risk of dying before age of five were born in rural areas, among the poor or to a mother denied basic education.

The efforts to reduce Infant and Child Mortality in Kenya have suffered a major setback since the emergence of HIV/AIDs pandemic in the late 1980s. HIV/AIDs is now one of the leading causes of death in many African countries.
HIV/AIDs pandemic has led to slowed decline in improvements in Infant and Child Mortality.

Kenya is ranked $39^{\text {th }}$ globally in under 5 deaths. Over 7 million children under 5 years of age die each year mainly from preventable and treatable conditions. Pneumonia, diarrhea and malaria remain the leading cause of child mortality and under nutrition contribute to more than $1 / 3$ of all deaths.

The impact of HIV/AIDs on Child Mortality is also well documented in a number of studies. HIV/AIDs affect childhood mortality through vertical transmission of the HIV virus from mother to child during birth and breast feeding which then puts the child at a very high risk of dying.

A number of studies have found increased mortality in HIV infected children compared to HIV non-infected children [2].

Some of the factors that lead to infant and child mortality include;

a) Bio-demographic factors:

A number of bio-demographic factors have been considered they have a direct influence on Infant and Child Mortality these factors include: Length preceding birth interval, birth order, age of the mother of a child, sex of child, birth weight and gestation at birth of the child.

b) Socio-economic factors: 
These include mother's and father's education, father's and mother's occupation, wealth index, place of residence and marital status of the mother.

c) Environmental factors:

They have a significant impact on Infant and Child Mortality. They are considered a source of exposure to disease causing agents. They include floor material, access to safe drinking water, and access to good sanitation facilities.

\subsection{Objectives of the Study}

The main objective of the study is to identify socioeconomic, demographic and environmental factors associated with Infant and Child mortality in Kenya.

\subsection{Problem Statement}

Infant and Child Mortality remains a great concern not only in Kenya but many countries in Africa.

Although Kenya has seen a significant decline in Mortality in the last decade, Infant and Child Mortality are still high. Studies have been conducted to identify covariates of infant and child mortality in Kenya but none of these have included HIV/AIDs as a risk factor hence the need for this study.

\subsection{Justification of the Study}

This study will help the Kenya Government, nongovernmental organizations and other partners in the health sector to know and understand the important areas they need to focus on in order to develop policies, programmed projects to reduce Infant and Child Mortality rates. It will add to the existing literature on Infant and Child Mortality in Kenya.

\subsection{Literature Review}

Fishel et al, their study focused on the covariate analysis of data from 20 surveys in 13 countries conducted under the DHs program between 2003 and 2012 in order to compare the levels of Child Mortality among children of HIV positive and HIV negative women. In their report they found out that across all surveys, in the analysis children with HIV positive women generally experience higher mortality rates than their counter parts who are HIV negative. Their results showed little evidence of improvement in the survival of children of HIV-positive women compared with children of HIV negative women.

Eduardo et al in their study they aimed to examine the impact of child HIV infection on mortality and to identify nutritional and socio-demographic factors that increase the risk of child mortality independent of HIV infection. They found out that HIV infection was a strong predictor of death among children who have been hospitalized with pneumonia. They also found out that preventable conditions like inadequate water, child under nutrition contribute significantly. [5]

Wambugu carried out his study to try and examine the factors that were associated with under 5 mortality during the upsurge period using KDHS 2003. His study showed that there was significant variation on the under-5 mortality between children in households with improved sources of drinking water. He also found out that use of non-improved water sources, short breast feeding periods, young mothers and large families were associated with increase cases of under -5 mortality. [11]

Mutangili in his study he tried to explore the effects of Mothers HIV status on Infant and Child Mortality at two levels, he also investigated the magnitude of the effects of some selected socio-economic, material and environmental factors on infant and child mortality. His study utilized the KDHS 2003 data from Kenya the results of his study showed that there was a significant association between child mortality (age 12 - 59) months and mothers HIV status in Kenya. [3]

Lemani in his study he aimed at examining biodemographic, socio-economic and environmental factors associated with infant child and child mortality in Malawi. The results of is study show that HIV status of the mother and length of the preceding birth interval were significantly associated with both infant and child mortality during both time periods. In his study he also considered other covariates such as birth order, age of the mother at birth of the child, education of the mother and father and wealth index. [2]

Muriithi in his study he aimed at examining the effect of socio-economic and demographic variables on infant and child mortality. He used the Cox regression analysis to compute relative risk of the socio-economic and demographic variables on infant and child mortality. His study revealed that both the socio-economic and demographic factors affect both infant and child mortality. He also found out that the place of birth had the greatest impact on infant mortality. [4]

Clifford et al examined socio-economic determinants of infant mortality in Kenya. They employed the logistic regression model in testing the magnitude of the significance of each selected variable on the 2003 KDHS data to study socio-economic determinants of infant mortality. [7]

Kayonde et al in their study they found out there was an increase in the likelihood of under-five mortality in homes with poor toilet facilities compared to homes with better toiled facilities. For infant mortality, improved toilets reduced the risk of infant death. [8]

Fulasi et al in their study they found out that infants whose mothers had no antenatal care follow up were 2-3 times likely to die than those whose mothers had at least one follow up. [1]

A study using world fertility survey data from 39 countries found higher mortality among teenage mothers among older mothers. [7]

Souza Investigated refusal biases in HIV data using the 2004 and 2010 malawi demographic and health survey. This study showed that the 2004 HIV data were more affected by refusal bias. [14]

Ghys et al found a significant relationship between infant mortality and the season of child births, maternal HIV infection but not with socio economic variables considered. Other significant variables included adult educational 
facilities. [12]

Odimegwu et al using 2003 DHS data set for children by using logistic regression models, examined socioeconomic determinants of infant mortality rate both in urban and rural setting. They found similar results like in the case of Tanzania, that regional variation exists in infant and child mortality between the different provinces of Kenya with increased risk in the rural areas. [9]

Bharati used data from 1993, 1998, and 2003 DHS surveys in Ghana to examine the determinants of infant and child mortality in three northern regions by using multivariate logistic regression model found that education of mothers, birth order of child and marital status of mothers are powerful significant determinants for infant mortality, while only mother's education have a significant impact for child mortality. [6]

Nidrangu indicated that children born to mothers with higher educational level associated with lower risk of infant and child mortality as compared to children born to mothers with primary education level or non-educated. [13]

\section{Methodology}

\subsection{Logistic Regression Model}

A logistic model predicts the probability that an outcome will be 1 or 0 for non-occurrence. The dependent variable in this model is a binary outcome taking the value of 1 if the event of interest occurs and 0 otherwise. In this case, the dependent variable takes the value of 1 if a death occurs among children in the age of segment of 0 to 11 months or 12 to 60 months and a value of 0 otherwise.

The logistic regression model is given by

$$
\pi_{i}=\frac{\exp \left(\beta_{0}+\beta_{i} x_{i}\right)}{1+\exp \left(\beta_{0}+\beta_{i} x_{i}\right)}
$$

Where

$\pi_{i}$ Is the probability that a death will occur for the $\mathrm{i}^{\text {th }}$ individual.

$\beta_{0}$ Is the intercept

$\beta_{i}$ Is the regression coefficient for the explanatory variable $x_{i}$.

Explain the logistic regression model

This method is based on the log transformation of the odds, the expression can also be written as:

$$
\operatorname{logit}\left(x_{i}\right)=\log \left(\frac{\pi_{i}}{1-\pi_{i}}\right)=\beta_{0}+\beta_{i} x_{i}
$$

Where $\left(\frac{\pi_{i}}{1-\pi_{i}}\right)$ is the odd of an event occurring in logistic

$$
l(\beta)=\left(\sum_{i=1}^{K} y_{i}\left(\sum_{K=0}^{K} \chi_{i k} \beta_{K}\right) \chi_{i k} \beta_{K}\right)-n_{i} \log \left(1+\exp \left(\sum_{K=0}^{K} \chi_{i K} \beta_{K}\right)\right)
$$

To obtain the critical points of the log likelihood function, set the first derivate with respect to each $\beta$ equal to zero. Differentiating equation (9) we get

$$
\frac{\partial}{\partial \beta_{k}} \sum_{k=0}^{k} \chi_{i k} \beta_{k}=\chi_{i k}
$$

regression analysis.

We only considered those fully exposed to the risk of death within period of interest. This is done to ensure that all births have the chance of dying by the age of interest.

The parameters in the logistic regression can be estimated by maximum likelihood. The maximum likelihood estimates can be computed numerically by using iteratively reweighted least squares.

\subsection{Parameter Estimation}

The regression coefficients are estimated by the method of maximum likelihood method.

Maximum Likelihood Method for Logistic Regression

Since each $y_{i}$ represents a binominal count in the $i^{\text {th }}$ population the joint probability function of $Y$ is

$$
f\left({ }^{y} / \beta\right)=\prod_{i=1}^{n} \frac{1}{y i\left(1-y_{i}\right)} \pi_{i}^{y_{i}}\left(1-\pi_{i}\right)^{1-y_{i}}
$$

The ML estimation are the values for $\beta$ that maximizes the likelihood function of equation (1). After rearranging the terms, the equation to be maximized can be written as

$$
\prod_{i=1}^{n}\left(\frac{\pi_{i}}{1-\pi_{i}}\right)^{y_{i}} 1-\pi_{i}^{n_{i}}
$$

The logistic regression model equates the logit transform to the log odds of the probability of success.

$$
\log \left(\frac{\pi_{i}}{1-\pi_{i}}\right)=\sum_{K=0}^{K} \chi_{K i} \beta_{K}
$$

Exponentiating both sides we get

$$
\left(\frac{\pi_{i}}{1-\pi_{i}}\right)=\exp \sum_{K=0}^{K} \chi_{K i} \beta_{K}
$$

Solving for $\pi_{i}$ we get

$$
\pi_{i}=\left[\frac{\left(\sum_{K=0}^{K} \chi_{i K} \beta_{K}\right)}{1+\exp \left(\sum_{K=0}^{K} \chi_{i K} \beta_{K}\right)}\right]
$$

Substituting equation 3 and 4 for the second term, equation 5 becomes

$$
\prod_{i=1}^{n}\left(\exp \left(\sum_{K=0}^{K} \chi_{i k} \beta_{K}\right)\right)^{y_{i}}\left(1-\frac{\exp \left(\sum_{K=0}^{K} \chi_{i K} \beta_{K}\right)}{1+\exp \left(\sum_{K=0}^{K} \chi_{i K} \beta_{K}\right)}\right) n_{i}
$$

Simplifying the first product equation 6 becomes

$$
\prod_{i=1}^{n}\left(\exp \left(y_{i} \sum_{K=0}^{K} \chi_{i k} \beta_{K}\right)\left(1+\exp \left(\sum_{K=0}^{K} \chi_{i K} \beta_{K}\right)\right)^{-n_{i}}\right.
$$

This is the kernel of the likelihood function to maximize. This can be simplified by taking logs so as to differentiate
Since the other term in the summation does not depend on $\beta_{k}$ they can be treated as constants. Differentiating the second half of equation (9) we get.

The maximum likelihood estimates for $\beta$ can be found by setting each of the $\mathrm{K}+1$ equations in equation (10) to zero 
and solving for each $\beta_{K}$.

$$
\begin{gathered}
\frac{\partial l(\beta)}{\partial \beta_{k}}=\sum_{i=1}^{n} y_{i} x_{i k}-\frac{1}{1+\exp \left(\sum_{K=0}^{K} \chi_{i K} \beta_{K}\right)} \frac{\partial}{\partial \beta_{k}}\left(1+\exp \left(\sum_{K=0}^{K} \chi_{i K} \beta_{K}\right)\right. \\
=\sum_{i=1}^{n} y_{i} x_{i k}-\frac{1}{1+\exp \left(\sum_{K=0}^{K} \chi_{i K} \beta_{K}\right)} \cdot \exp \left(\sum_{K=0}^{K} \chi_{i K} \beta_{K}\right) \frac{\partial}{\partial \beta_{k}} \sum_{K=0}^{K} \chi_{i K} \beta_{K} \\
=\sum_{i=1}^{n} y_{i} x_{i k}-\frac{1}{1+\exp \left(\sum_{K=0}^{K} \chi_{i K} \beta_{K}\right)} \cdot \exp \left(\sum_{K=0}^{K} \chi_{i K} \beta_{K}\right) \cdot \chi_{i K} \\
=\sum_{i=1}^{n} y_{i} x_{i k}-\pi_{i} x_{i k}
\end{gathered}
$$

\subsection{Survival Analysis}

Survival analysis methods are used to model time of occurrence of an event. The response variable is the waiting time to the occurrence of the event of interest.

\subsubsection{The Kaplan - Meier Survival Analysis}

Kaplan - Meier survival analysis is a non-parametric method for estimating the survivor function $(S(t))$, which is the probability of surviving beyond time $(t)$. It uses the exact survival time for each individual in the sample as compared to life table method which group the survival time into intervals.

Random numbers were used to estimate the date of birth and date of death for the infant and children in this analysis. In general, the distribution of survival times is given by a survival functions.

$S(t)=\operatorname{Pr}(T>t)$, Where $\mathrm{T}$ is a continuous random variable representing survival time.

\subsubsection{Parametric Regression Model}

The Kaplan - Meier survival analysis method investigates the impact of each of the covariates independently on the survival time infants and children.

To investigate the significance of a covariate in influencing the response in the presence of other covariates, we use a multivariate parametric regression model with an exponential distribution.

The survivor function for the survival exponential model is given by the expression:

$$
S(t)=\exp \left(-\lambda_{i} t_{i}\right)
$$

Where

$\lambda_{i}$ Is a parameter and

$t$ is time

The survivor function can be written as

$$
S(t)=\exp \left(-\exp \left(\beta_{0}+\beta_{i} x_{i}\right)\right)
$$

$\beta_{0}$ Is the intercept xi

$\beta_{i}$ Is the regression coefficient for the explanatory variable $t$ Is time

The exponential parametric model can also be written in form of hazards and is given by the formular:

$$
h(t)=h_{0}(t) \exp \left(\beta_{i} x_{i}\right)
$$

Where

$h(t)$ Is the hazard at time $\mathrm{t}$

$h_{0}(t)$ Is the baseline hazard

$\beta_{i}$ Is the regression coefficient

$x_{i}$ Is the covariate

Description of covariates

The variables are coded to form categorical factors for the purpose of analysis. They are grouped into three main groups bio-demographic, socio-economic and environmental factors.

\section{Results and Discussions}

\subsection{Multivariate Logistic Regression}

Multivariate logistic regression is used to test the significance of the independent variables in influencing the response variable in the presence of the other variables.

\subsection{Logistic Regression for Infants}

The fifteen covariates were first included in the model. Five of them were dropped from the final model one at a time as they were found to be insignificant and their presence has no significant impact on the model. The factors included father's occupation, mother's occupation, status region of residence, father's education and source of drinking water.

In total 3000 observations from 2010 DHS and 5000 observations from 2014 DHS were used for the infant logistic regression model.

The table below represents the results of a multivariate logistic regression analysis for the two time periods.

Two bio-demographic covariates were found to be significant in influencing the risk of death during infancy. The two factors are HIV status of the mother and preceding birth interval. In 2014 these covariates were significant, HIV status of the mother preceding birth interval and mother's education. 
Table 1. Multiple Logistic Regression Results for Infants.

\begin{tabular}{|c|c|c|c|c|c|c|}
\hline \multirow{2}{*}{ Covariate } & \multicolumn{2}{|l|}{2010 DHS } & \multirow{2}{*}{ P-value } & \multicolumn{2}{|l|}{2014 DHS } & \multirow{2}{*}{ P-value } \\
\hline & Odds Ratio & Standard error & & Odds ratio & Standard error & \\
\hline \multicolumn{7}{|l|}{ HIV Status } \\
\hline Negative (Ref) & 1.000 & & & 1.000 & & \\
\hline Positive & 4.595 & 2.535 & 0.000 & 3.975 & 1.932 & 0.001 \\
\hline Not tested & 1.585 & 0.496 & 0.142 & 1.888 & 0.429 & 0.002 \\
\hline \multicolumn{7}{|l|}{ Birth Order } \\
\hline First births (Ref) & 1.000 & & & 1.000 & & \\
\hline $2-4$ & 0.698 & 0.188 & 0.184 & 1.165 & 0.660 & 0.787 \\
\hline 5 and above & Omitted & & & Omitted & & \\
\hline \multicolumn{7}{|l|}{ Birth Interval } \\
\hline 9-23 months (Ref) & 1.000 & & & 1.000 & & \\
\hline $24-35$ months & 0.491 & 0.162 & 0.032 & 0.381 & 0.112 & 0.001 \\
\hline 36-47 months & 0.322 & 0.121 & 0.003 & 0.556 & 0.169 & 0.055 \\
\hline 48-59 months & 0.803 & 0.358 & 0.624 & 0.576 & 0.193 & 0.102 \\
\hline 60-259 months & 0.328 & 0.159 & 0.022 & 0.826 & 0.273 & 0.565 \\
\hline First births & 0.531 & 0.206 & 0.105 & 1.894 & 1.561 & 0.438 \\
\hline \multicolumn{7}{|l|}{ Mother's Education } \\
\hline No education (Ref) & 1.000 & & & & & \\
\hline Primary & 1.744 & 0.523 & 0.064 & 1.317 & 0.946 & 0.702 \\
\hline Secondary + & 0.784 & 0.437 & 0.664 & 0.156 & 0.145 & 0.047 \\
\hline \multicolumn{7}{|l|}{ Wealth Index } \\
\hline Poorer (Ref) & 1.000 & & & 1.000 & & \\
\hline Poor & 1.083 & 0.356 & 0.809 & 1.623 & 0.439 & 0.074 \\
\hline Middle & 1.096 & 0.336 & 0.765 & 1.651 & 0.487 & 0.090 \\
\hline Rich & 1.198 & 0.487 & 0.657 & 1.128 & 0.369 & 0.711 \\
\hline Richer & 0.810 & 0.402 & 0.627 & 0.719 & 0.381 & 0.535 \\
\hline \multicolumn{7}{|l|}{ Sex of the child } \\
\hline Female (Ref) & 1.000 & & & 1.000 & & \\
\hline Male & 0.898 & 0.155 & 0.538 & 1.102 & 0.182 & 0.554 \\
\hline \multicolumn{7}{|l|}{ Type of residence } \\
\hline Rural (Ref) & 1.000 & & & 1.000 & & \\
\hline Urban & 0.538 & 0.255 & 0.192 & 1.521 & 0.494 & 0.196 \\
\hline \multicolumn{7}{|l|}{ Floor material } \\
\hline Unfinished (Ref) & 1.000 & & & 1.000 & & \\
\hline Finished & 1.705 & 0.622 & 0.144 & 1.447 & 0.539 & 0.320 \\
\hline \multicolumn{7}{|l|}{ Toilet facility } \\
\hline No toilet (Ref) & 1.000 & & & 1.000 & & \\
\hline Traditional & 1.113 & 0.312 & 0.701 & 0.811 & 0.192 & 0.380 \\
\hline Improved toilet & 0.674 & 0.605 & 0.661 & 2.032 & 1.035 & 0.164 \\
\hline \multicolumn{7}{|l|}{ Marital Status } \\
\hline Not married (Ref) & 1.000 & & & 1.000 & & \\
\hline Married & 0.669 & 0.179 & 0.135 & 0.969 & 0.229 & 0.897 \\
\hline \multicolumn{7}{|l|}{ Mother's age } \\
\hline Less than 20 years (Ref) & 1.000 & & & 1.000 & & \\
\hline 20-34 years & 0.905 & 0.269 & 0.739 & 0.956 & 0.273 & 0.877 \\
\hline $35+$ & 0.838 & 0.450 & 0.743 & 1.955 & 0.738 & 0.076 \\
\hline
\end{tabular}

The odds of dying for infants whose mothers were HIV positive was 4/595 times higher relative to those infants born to HIV negative mothers in 2010. In 2014 the odds were statistically different as those whose mothers tested were 1.888 likely to die than those mothers tested HIV negative.

The length of the preceding birth interval was also significant as a predictor of infant's mortality in both 2010 and 2014. It can be noted that from table 1 none of the environmental factors are statistically significant in influencing the risk of death for infants.

\subsection{Logistic Regression for the Risk of Death During Childhood}

This section presents the results of logistic regression analysis for the co-factors affecting deaths of children aged
1-5. Information from 9745 children and 19653 children from 2010 and 2014 DHS were used in the logistic regression models for children. The table 2 shows the results.

Four bio-demographic and one socio-economic variable were found to be significant in 2010 of which one (birth order) was found not significant.

In 2014, HIV status of the mothers had a significant impact on child death but not in 2010. Children of HIV positive mothers were almost twice likely to die compared to those whose mothers were HIV negative.

The preceding birth interval was also significant in influencing child mortality with the odds of dying declining as the interval increases in both time periods.

Children whose mothers were aged 20-34 at the time of their birth were less likely to die with odds ratios of 0.695 
and 0.825 in 2010 and 2014 respectively.

Another important factor is mother's education which was significant in both 2010 and 2014. The risk of death among children whose mothers had primary education and secondary education was 0.645 and 0.517 times that of children whose mothers had no education in 2014.

Table 2. Multiple Logistic Regression Results for Children aged 1 to 5.

\begin{tabular}{|c|c|c|c|c|c|c|}
\hline \multirow{2}{*}{ Covariate } & \multicolumn{2}{|l|}{2010 DHS } & \multirow{2}{*}{ P-value } & \multicolumn{2}{|l|}{2014 DHS } & \multirow{2}{*}{ P-value } \\
\hline & Odds Ratio & Standard error & & Odds ratio & Standard error & \\
\hline \multicolumn{7}{|l|}{ HIV Status } \\
\hline Negative (Ref) & 1.000 & & & 1.000 & & \\
\hline Positive & 1.442 & 0.279 & 0.059 & 2.150 & 0.272 & 0.000 \\
\hline Not tested & 0.920 & 0.078 & 0.330 & 1.023 & 0.065 & 0.720 \\
\hline \multicolumn{7}{|l|}{ Birth Order } \\
\hline First births (Ref) & 1.000 & & & 1.000 & & \\
\hline $2-4$ & 1.587 & 0.171 & 0.000 & 0.893 & 0.176 & 0.569 \\
\hline 5 and above & 1.841 & 0.240 & 0.000 & 1.064 & 0.240 & 0.782 \\
\hline \multicolumn{7}{|l|}{ Birth Interval } \\
\hline 9-23 months (Ref) & 1.000 & & & 1.000 & & \\
\hline 24-35 months & 0.576 & 0.052 & 0.000 & 0.633 & 0.095 & 0.003 \\
\hline 36-47 months & 0.375 & 0.050 & 0.000 & 0.340 & 0.062 & 0.000 \\
\hline $48-59$ months & 0.354 & 0.066 & 0.000 & 0.254 & 0.056 & 0.000 \\
\hline $60-259$ months & 0.317 & 0.055 & 0.000 & 0.288 & 0.065 & 0.000 \\
\hline First births & Omitted & & & Omitted & & \\
\hline \multicolumn{7}{|l|}{ Mother's Education } \\
\hline No education (Ref) & 1.000 & & & 1.000 & & \\
\hline Primary & 0.920 & 0.071 & 0.286 & 0.637 & 0.109 & 0.009 \\
\hline Secondary + & 0.576 & 0.110 & 0.004 & 0.516 & 0.119 & 0.004 \\
\hline \multicolumn{7}{|l|}{ Father's Education } \\
\hline No education (Ref) & 1.000 & & & 1.000 & & \\
\hline Primary & 0.922 & 0.079 & 0.347 & 0.956 & 0.080 & 0.603 \\
\hline Secondary + & 0.875 & 0.107 & 0.277 & 0.721 & 0.086 & 0.007 \\
\hline \multicolumn{7}{|l|}{ Wealth Index } \\
\hline Poorer (Ref) & 1.000 & & & 1.000 & & \\
\hline Poor & 0.932 & 0.104 & 0.536 & 0.968 & 0.084 & 0.716 \\
\hline Middle & 0.920 & 0.105 & 0.473 & 1.035 & 0.089 & 0.684 \\
\hline Rich & 0.878 & 0.108 & 0.292 & 0.981 & 0.096 & 0.851 \\
\hline Richer & 0.914 & 0.214 & 0.704 & 1.171 & 0.207 & 0.372 \\
\hline \multicolumn{7}{|l|}{ Sex of the Child } \\
\hline Female (Ref) & 1.000 & & & 1.000 & & \\
\hline Male & 1.194 & 0.078 & 0.007 & 1.207 & 0.069 & 0.001 \\
\hline \multicolumn{7}{|l|}{ Type of Residence } \\
\hline Rural (Ref) & 1.000 & & & 1.000 & & \\
\hline Urban & 0.842 & 0.103 & 0.163 & 0.895 & 0.106 & 0.355 \\
\hline \multicolumn{7}{|l|}{ Floor Material } \\
\hline Unfinished (Ref) & 1.000 & & & 1.000 & & \\
\hline Finished & 0.739 & 0.132 & 0.091 & 0.864 & 0.115 & 0.279 \\
\hline \multicolumn{7}{|l|}{ Toilet Facility } \\
\hline No toilet (Ref) & 1.000 & & & 1.000 & & \\
\hline Traditional & 0.897 & 0.088 & 0.270 & 0.931 & 0.077 & 0.396 \\
\hline Improved toilet & 0.819 & 0.187 & 0.384 & 0.793 & 0.149 & 0.219 \\
\hline \multicolumn{7}{|l|}{ Marital Status } \\
\hline Not married (Ref) & 1.000 & & & 1.000 & & \\
\hline Married & 0.813 & 0.086 & 0.053 & 0.794 & 0.064 & 0.004 \\
\hline \multicolumn{7}{|l|}{ Mother's age } \\
\hline Less than 20 years (Ref) & 1.000 & & & 1.000 & & \\
\hline $20-34$ years & 0.905 & 0.269 & 0.739 & 0.956 & 0.273 & 0.877 \\
\hline $35+$ & 0.838 & 0.450 & 0.743 & 1.955 & 0.738 & 0.076 \\
\hline
\end{tabular}

\section{Survival Analysis}

Survival analysis is important as a complement to the logistic regression analysis.

Multivariate Survival Analysis

This section presents the findings of the multivariate survival analysis.

\subsection{Multivariate Survival Analysis for Infants}

Table 3 shows the results of a multivariate survival regression for covariates of infant mortality using both 2010 and 2014 DHS. As it was with multivariate logistic regression, father's occupation; mother's occupation and father's education were dropped in the final model.

Women who tested HIV positive had increased risk of experiencing an infant death compared to those who tested 
HIV negative in both time periods. This was statistically significant with P-values of 0.003 in 2010 and 0.002 in 2014.

Wealth index had a significant influence on infant mortality only in 2010. Infants from poor and middle households experienced double risk of mortality as infants from poorer household. Birth order was found to be insignificant in the multivariate survival analysis for infants.

Table 3. Multiple Survival Regression Results for Infants.

\begin{tabular}{|c|c|c|c|c|c|c|}
\hline \multirow{2}{*}{ Covariate } & \multicolumn{2}{|l|}{2010 DHS } & \multirow{2}{*}{ P-value } & \multicolumn{2}{|l|}{2014 DHS } & \multirow{2}{*}{ P-value } \\
\hline & Hazard ratio & Standard error & & Hazard error & Standard error & \\
\hline \multicolumn{7}{|l|}{ HIV Status } \\
\hline Negative (Ref) & 1.000 & & & 1.000 & & \\
\hline Positive & 2.883 & 1.005 & 0.003 & 2.442 & 0.701 & 0.002 \\
\hline Not tested & 1.182 & 0.248 & 0.427 & 1.519 & 0.228 & 0.006 \\
\hline \multicolumn{7}{|l|}{ Birth Order } \\
\hline First births (Ref) & 1.000 & & & 1.000 & & \\
\hline 5 and above & 1.029 & 0.351 & 0.932 & 1.465 & 0.394 & 0.156 \\
\hline \multicolumn{7}{|l|}{ Birth Interval } \\
\hline 9-23 months (Ref) & 1.000 & & & 1.000 & & \\
\hline 24-35 months & 0.509 & 0.125 & 0.006 & 0.310 & 0.100 & 0.000 \\
\hline 36-47 months & 0.466 & 0.123 & 0.004 & 0.479 & 0.158 & 0.027 \\
\hline 48-59 months & 0.782 & 0.285 & 0.500 & 0.236 & 0.121 & 0.005 \\
\hline 60-259 months & 0.372 & 0.136 & 0.007 & 0.585 & 0.206 & 0.130 \\
\hline First births & Omitted & & & Omitted & & \\
\hline No education (Ref) & 1.000 & & & 1.000 & & \\
\hline Primary & 1.023 & 0.211 & 0.910 & 1.243 & 0.252 & 0.283 \\
\hline Secondary + & 0.528 & 0.190 & 0.078 & 1.102 & 0.358 & 0.764 \\
\hline \multicolumn{7}{|l|}{ Wealth Index } \\
\hline Poorer (Ref) & 1.000 & & & 1.000 & & \\
\hline Poor & 1.198 & 0.278 & 0.438 & 2.063 & 0.401 & 0.000 \\
\hline Middle & 1.099 & 0.261 & 0.691 & 1.616 & 0.331 & 0.019 \\
\hline Rich & 1.096 & 0.319 & 0.751 & 1.338 & 0.309 & 0.208 \\
\hline Richer & 1.088 & 0.526 & 0.860 & 1.740 & 0.621 & 0.212 \\
\hline \multicolumn{7}{|l|}{ Sex of the Child } \\
\hline Female (Ref) & 1.000 & & & 1.000 & & \\
\hline Male & 1.123 & 0.148 & 0.377 & 1.361 & 0.183 & 0.022 \\
\hline \multicolumn{7}{|l|}{ Type of Residence } \\
\hline Rural (Ref) & 1.000 & & & 1.000 & & \\
\hline Urban & 0.617 & 0.217 & 0.172 & 1.123 & 0.391 & 0.738 \\
\hline Finished & 1.152 & 0.411 & 0.691 & 1.086 & 0.271 & 0.738 \\
\hline \multicolumn{7}{|l|}{ Toilet Facility } \\
\hline No toilet (Ref) & 1.000 & & & 1.000 & & \\
\hline Traditional & 1.230 & 0.256 & 0.320 & 0.731 & 0.140 & 0.103 \\
\hline Improved toilet & 1.226 & 0.735 & 0.685 & 0.690 & 0.252 & 0.311 \\
\hline \multicolumn{7}{|l|}{ Marital Status } \\
\hline Not married (Ref) & 1.000 & & & & & \\
\hline Married & 0.671 & 0.133 & 0.046 & 0.799 & 0.147 & 0.227 \\
\hline \multicolumn{7}{|l|}{ Mother's age } \\
\hline Less than 20 years (Ref) & 1.000 & & & 1.000 & & \\
\hline $20-34$ years & 1.026 & 0.242 & 0.910 & 0.775 & 0.152 & 0.197 \\
\hline $35+$ & 1.084 & 0.412 & 0.831 & 1.296 & 0.347 & 0.332 \\
\hline
\end{tabular}

\subsection{Multivariate Survival Analysis for Children}

This section represents results of multiple survival regression for children aged 1 to 5 . The results for this section are presented in table 4.

Table 4. Multiple Survival Regression Results for Children aged 1 to 5.

\begin{tabular}{|c|c|c|c|c|c|c|}
\hline \multirow{2}{*}{ Covariate } & \multicolumn{2}{|l|}{2010 DHS } & \multirow{2}{*}{ P-value } & \multicolumn{2}{|l|}{2014 DHS } & \multirow{2}{*}{ P-value } \\
\hline & Hazard ratio & Standard error & & Hazard ratio & Standard error & \\
\hline \multicolumn{7}{|l|}{ HIV Status } \\
\hline Negative (Ref) & 1.000 & & & 1.000 & & \\
\hline Positive & 3.204 & 0.915 & 0.000 & 3.842 & 0.890 & 0.000 \\
\hline Not tested & 1.316 & 0.251 & 0.151 & 1.613 & 0.24528 & 0.002 \\
\hline
\end{tabular}




\begin{tabular}{|c|c|c|c|c|c|c|}
\hline \multirow{2}{*}{ Covariate } & \multicolumn{2}{|l|}{2010 DHS } & \multirow{2}{*}{ P-value } & \multicolumn{2}{|l|}{2014 DHS } & \multirow{2}{*}{ P-value } \\
\hline & Hazard ratio & Standard error & & Hazard ratio & Standard error & \\
\hline \multicolumn{7}{|l|}{ Birth Order } \\
\hline First births (Ref) & 1.000 & & & 1.000 & & \\
\hline $2-4$ & 1.149 & 0.495 & 0.747 & 5.833 & 3.760 & 0.006 \\
\hline 5 and above & 1.522 & 0.653 & 0.328 & 4.179 & 2.705 & 0.027 \\
\hline \multicolumn{7}{|l|}{ Birth Interval } \\
\hline 9-23 months (Ref) & 1.000 & & & 1.000 & & \\
\hline $24-35$ months & 0.655 & 0.130 & 0.034 & 0.475 & 0.084 & 0.000 \\
\hline 36-47 months & 0.422 & 0.113 & 0.001 & 0.506 & 0.091 & 0.000 \\
\hline 48-59 months & 0.603 & 0.172 & 0.077 & 0.436 & 0.116 & 0.002 \\
\hline $60-259$ months & 0.475 & 0.145 & 0.016 & 0.386 & 0.098 & 0.000 \\
\hline First births & Omitted & & & Omitted & & \\
\hline \multicolumn{7}{|l|}{ Mother's Education } \\
\hline No education (Ref) & 1.000 & & & 1.000 & & \\
\hline Primary & 0.859 & 0.321 & 0.685 & 0.911 & 0.154 & 0.587 \\
\hline Secondary + & 0.222 & 0.148 & 0.895 & 0.782 & 0.160 & 0.232 \\
\hline \multicolumn{7}{|l|}{ Father's Education } \\
\hline No education (Ref) & 1.000 & & & 1.000 & & \\
\hline Primary & 1.098 & 0.237 & 0.664 & 0.911 & 0.154 & 0.587 \\
\hline Secondary + & 0.965 & 0.256 & 0.895 & 0.782 & 0.160 & 0.232 \\
\hline \multicolumn{7}{|l|}{ Wealth Index } \\
\hline Poorer (Ref) & 1.000 & & & 1.000 & & \\
\hline Poor & 1.012 & 0.204 & 0.951 & 1.230 & 0.198 & 0.199 \\
\hline Middle & 1.124 & 0.231 & 0.568 & 1.027 & 0.196 & 0.886 \\
\hline Rich & 0.801 & 0.200 & 0.378 & 1.214 & 0.233 & 0.313 \\
\hline Richer & 0.670 & 0.306 & 0.383 & 0.801 & 0.240 & 0.460 \\
\hline \multicolumn{7}{|l|}{ Sex of the Child } \\
\hline Female (Ref) & 1.000 & & & 1.000 & & \\
\hline Male & 1.402 & 0.227 & 0.037 & 1.192 & 0.128 & 0.104 \\
\hline \multicolumn{7}{|l|}{ Type of Residence } \\
\hline Rural (Ref) & 1.000 & & & 1.000 & & \\
\hline Urban & 1.093 & 0.342 & 0.775 & 0.823 & 0.265 & 0.547 \\
\hline \multicolumn{7}{|l|}{ Floor Material } \\
\hline Unfinished (Ref) & 1.000 & & & 1.000 & & \\
\hline Finished & 1.137 & 0.418 & 0.726 & 0.729 & 0.154 & 0.136 \\
\hline \multicolumn{7}{|l|}{ Toilet Facility } \\
\hline No toilet (Ref) & 1.000 & & & 0.959 & & \\
\hline Traditional & 0.959 & 0.171 & 0.816 & 1.649 & 0.179 & 0.826 \\
\hline Improved toilet & 1.215 & 0.652 & 0.716 & & 0.585 & 0.159 \\
\hline \multicolumn{7}{|l|}{ Marital Status } \\
\hline Not married (Ref) & 1.000 & & & 1.000 & & \\
\hline Married & 0.611 & 0.711 & 0.011 & 0.668 & 0.114 & 0.019 \\
\hline \multicolumn{7}{|l|}{ Mother's age } \\
\hline Less than 20 years (Ref) & 1.000 & & & 1.000 & & \\
\hline $20-34$ years & 1.134 & 0.221 & 0.517 & 1.362 & 0.288 & 0.144 \\
\hline $35+$ & 1.251 & 0.386 & 0.468 & 2.045 & 0.554 & 0.008 \\
\hline
\end{tabular}

HIV status of the mother still had a significant impact on children's mortality in both 2010 and 2014. Children whose mothers tested positive had hazard ratios of dying of 3.024 in 2010 and 3.482 in 2014 relative to those whose mothers tested negative. The impact of birth order was only significant in 2014 with children of order 2-4 and 5 and above experiencing higher mortality than first births with Pvalues of 0.006 and 0.027 respectively.

As it was with infant mortality, length of the preceding birth interval has an impact on child death in both 2010 and 2014.

In 2010 children whose mothers had at least secondary education had almost 0.8 times lower risk of dying compared to those whose mothers had no education. The impact of mother's education was not significant in 2014.

\section{Conclusion}

The study sought to identify factors associated with infant and child mortality in Kenya. It used the 2010 and 2014 MDHS and applied logistic regression and survival analysis. The results show that the demographic factors are strongly associated with infant mortality while demographic and socio-economic factors are significant in influencing child mortality HIV status of the mother and length preceding birth interval was found mortality using data from both time periods.

HIV status of the mother and length preceding birth interval were also significantly associated with child 
mortality in both time periods. Children born to HIV mothers were more likely to die compared to those born to HIV negative mothers. None of the environmental factors have been found to be significantly associated with both infant and child mortality.

The study provides insights into the risks factors of infant and child mortality in Kenya, which contains vital information for health policy makers in government and nongovernmental organizations. According to the study there is a need to scale up prevention of mother to child transmission (PMTCT) services and early HIV diagnosis and treatment in order to reduce infant and child deaths among children born to HIV positive mothers.

\section{Authors' Contributions}

All the authors have significant contribution to this paper and the final form of this paper is approved by all authors.

\section{Conflicts of Interest}

The author (s) declare (s) that there is no conflict of interest regarding the publication of this article.

\section{References}

[1] Akanni A. O and Fulasi "Determinants of Child Mortality in Rural Nigeria," World Rural Observations 4 (2): 38-45.

[2] Clara Lemani (2013) University of Cape town.

[3] Cornelius Mwisa Mutangili published on Population Studies and Research Institute University of Nairobi Kenya.

[4] Daniel Mwangi Muriithi: American Journal of Theoretical and Applied Statistics Vol. 4 - No. 5. Pp 404-413.
[5] Eduardo V., Lara Misegades" International Journal of Epidemiology '2005 34: 61-68 Vol. 34 no. 1.

[6] Ghosh, R and Bharati 2010"Determinants of infant and child mortality in periurbban areas of kolkala city India"Asoa pacific journal of public health 22 .

[7] Hisham. E. M and Clifford, O (2008) "Socio-economic Determinants of Infant Mortality in Kenya".

[8] Kayonde, G A 2012 Risk Factors and Predictive Model for under-five Mortality in Nigeria. Biomed Central, Pregnancy and Child Birth. 12 (10).

[9] Mustafa, H. E and C Odimegwu. 2008 "Socio economic determinants of infant mortality in Kenya. Analysis of kenya DHS 2003" Humanities and social sciences 2 (2) 1-16.

[10] Mutinga, C. S 2007. Environmental determinants of child mortality in kenya. katajanokanlaituri 6B, 00160 Helsinki Finland 6B: world institute for.

[11] Mwangi Wambugu University of Nairobi (2012) Nairobi. Unpublished thesis.

[12] Newel, M. H, Brahmhatt and P. D Ghys 2004,"child mortality and HIV infection in Africa: review", AIDS 18 (2): 527-534.

[13] Ndirangu, J. M. Newel, C Thorne and R Bland 2012 Treating H. I. V infected mother reduces under five years of age mortality to levels seen in children of H. I. V uninfected mothers in rural south Africa "Antiviral therapy."17: 81-90.

[14] Souza, E. M. 2012 "The impact of HIV on fertility in Malawi" unpublished thesis university of cape town.

[15] USAID (2014) written by Joy Fishel, Ruilin Ren Bernard Barrere.

[16] UNICEF (2011), HIV and AIDS estimates Geneva, Switzerland. 